\title{
Knowledge translation: evidence into action
}

\section{Don Nutbeamn,a,e and Andrew J Milatb,d}

a Sax Institute, Sydney, NSW, Australia

${ }^{b}$ NSW Ministry of Health, Sydney, Australia

${ }^{c}$ Editor-in-Chief, Public Health Research \& Practice

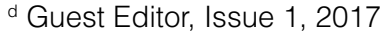

e Corresponding author: don.nutbeam@saxinstitute.org.au

\section{Article history}

Publication date: February 2017

Citation: Nutbeam D, Milat AJ. Knowledge translation: evidence into action. Public Health Res Pract. 2017;27(1):e2711700. doi: http://dx.doi.org/10.17061/phrp2711700
Few would disagree that public health policy should be evidence based; however, in real life, as many of our readers would know, this is not always the case. This themed issue of Public Health Research \& Practice examines knowledge translation to support policy and public health practice.

Policy making is a complex process, and available research evidence can be used in a variety of ways to lead, justify or support the development of policy. Policy develops and changes on the basis of underlying beliefs about the cause of a problem and the potential effects of an intervention, as well as consideration of the social and political context in which action is taken. Available evidence is set alongside these other more overtly political considerations.

Given such complexity, it would be foolish to imagine that there will ever be a simple and smooth transfer of evidence into the policy making process. The types of evidence used and the way that evidence is practically applied in policy processes will vary. Information can be used internally to monitor, analyse and critique policy options, or externally to persuade or mobilise others into action. Policy making is rarely an 'event', or even an explicit set of decisions derived from an appraisal of evidence and following a preplanned course. Policy tends to evolve through an iterative process that responds to the context within which it operates, and is subject to continuous review and incremental change. Policy making is an inherently 'political' process, and the timing of decisions is usually dictated as much by political considerations as by the state of the evidence.

In this context, policy change depends on an appraisal of what is scientifically plausible (evidence based); what is politically acceptable or achievable (fit with vision); and what is practical for implementation, at that point in time. It follows that policy is more likely to be influenced by evidence if the evidence is available and accessible at the time it is needed; the evidence is presented in a way that is sensitive to the political and social context; the evidence points to actions for which powers and resources are (or could be) available; and the systems, structures and capacity for action exist.

In a political context, evidence can be used in highly selective ways. Those with vested interests are adept at exploiting the normal uncertainty of research findings to delay a decision until "more evidence is gathered". The paper by Atkinson and colleagues in this issue provides an excellent example of a sophisticated use of dynamic simulation modelling to help manage the 
complexity arising from these different interests in the development of policy responses - in this example, examining alcohol-related harms.

Researchers will often claim their work is ignored without making an effort to understand that policy making is complex, often messy and driven by many considerations, of which available research findings are just one. But it's too simplistic to suggest that researchers are a vain lot who care solely about displaying their academic prowess and are indifferent to whether their work has impact. In general, they care deeply about their ability to make a difference. Too often, they encounter barriers to communication with policy makers, and respond to career incentives that take them away from the practical application of their research. The paper by Thackway and colleagues describes different approaches to rebalancing these incentives through funding programs that encourage coproduction of research, and support more and better translational research connected to state health priorities. And the paper by Wutzke and colleagues argues that coproduced partnership research is one of the most effective ways to increase the use of research in policy and practice.

Our collective challenge is to find ways of ensuring that evidence forms part of an inherently fluid political decision making process. This is a responsibility for both those who generate evidence (researchers and policy makers), and those who wish to see it used (health practitioners and advocates). Our interview with a former health minister, Nicola Roxon, reminds us of the challenge to provide timely access to information, and to employ improved techniques for communicating and managing the inevitable uncertainties that arise through scientific research. For the public servants who use evidence in policy making, there is the challenge to develop skills in the critical appraisal of evidence, and to judge how to achieve the best 'fit' between available evidence, current political priorities, and practical actions to achieve the desired outcomes. The paper by O'Donoughue, Jenkins and Anstey describes a practical response to this challenge through the use of secondments.

Achieving a shift towards evidence-informed policy doesn't necessarily require major improvements in the scientific quality of evidence. Rather, it requires improvements in the way in which available evidence is both communicated and received by policy makers and practitioners, and some of the important frameworks that can support this shift are reviewed by Milat and Li in this issue. Researchers must recognise that evidence is but one of a range of factors that will ultimately influence their decision making. Researchers need to work with policy makers and practitioners to understand more clearly the type of questions that need answering, and to continue to develop the research methods that deliver the best possible answers to questions of greatest public health importance.

We hope our readers enjoy these themed papers and all the articles in this issue. We'd also like to thank our dedicated band of peer reviewers, without whom we would not be able to bring you the high-quality, relevant public health articles that we strive to publish. We are most grateful for your support and collective wisdom.

\section{Copyright: (c)}

(C) 2017 Nutbeam and Milat. This article is licensed under the Creative Commons Attribution-NonCommercial-ShareAlike 4.0 International Licence, which allows others to redistribute, adapt and share this work non-commercially provided they attribute the work and any adapted version of it is distributed under the same Creative Commons licence terms. See: www.creativecommons.org/licenses/by-nc-sa/4.0/ 